\title{
Self-reported halitosis and emotional state: impact on oral conditions and treatments
}

\author{
Salvatore Settineri ${ }^{1 *}$, Carmela Mento ${ }^{1}$, Simona C Gugliotta ${ }^{1}$, Ambra Saitta ${ }^{1}$, Antonella Terranova², \\ Giuseppe Trimarchi ${ }^{3}$, Domenico Mallamace ${ }^{1}$
}

\begin{abstract}
Background: Halitosis represents a common dental condition, although sufferers are often not conscious of it. The aim of this study was to examine behavior in a sample of Italian subjects with reference to self-reported halitosis and emotional state, and specifically the presence of dental anxiety.

Methods: The study was performed on Italian subjects ( $N=1052$; range 15-65 years). A self-report questionnaire was used to detect self-reported halitosis and other variables possibly linked to it (sociodemographic data, medical and dental history, oral hygiene, and others), and a dental anxiety scale (DAS) divided into two subscales that explore a patient's dental anxiety and dental anxiety concerning dentist-patient relations. Associations between self-reported halitosis and the abovementioned variables were examined using multiple logistic regression analysis. Correlations between the two groups, with self-perceived halitosis and without, were also investigated with dental anxiety and with the importance attributed to one's own mouth and that of others.

Results: The rate of self-reported halitosis was 19.39\%. The factors linked with halitosis were: anxiety regarding dentist patient relations (relational dental anxiety) $(\mathrm{OR}=1.04, \mathrm{Cl}=1.01-1.07)$, alcohol consumption $(\mathrm{OR}=0.47, \mathrm{Cl}=$ 0.34-0.66), gum diseases $(\mathrm{OR}=0.39, \mathrm{Cl}=0.27-0.55)$, age $>30$ years $(\mathrm{OR}=1.01, \mathrm{Cl}=1.00-1.02)$, female gender $(\mathrm{OR}=$ $0.71, \mathrm{Cl}=0.51-0.98)$, poor oral hygiene $(\mathrm{OR}=0.65, \mathrm{Cl}=0.43-0.98)$, general anxiety $(\mathrm{OR}=0.66, \mathrm{Cl}=0.49-0.90)$, and urinary system pathologies $(\mathrm{OR}=0.46, \mathrm{Cl}=0.30-0.70)$. Other findings emerged concerning average differences between subjects with or without self-perceived halitosis, dental anxiety and the importance attributed to one's own mouth and that of others.
\end{abstract}

Conclusions: Halitosis requires professional care not only by dentists, but also psychological support as it is a problem that leads to avoidance behaviors and thereby limits relationships. It is also linked to poor self care. In the study population, poor oral health related to self-reported halitosis was associated with dental anxiety factors.

\section{Background}

Halitosis is a term used to describe oral malodor and is a common reason for seeking professional dental care. Some studies have estimated the prevalence of halitosis to be between $22 \%$ and $50 \%$, others between $6 \%$ and $23 \%[1,2]$. According to the American Dental Association, $50 \%$ of the adult population have suffered from an occasional oral malodor disorder, while $25 \%$ appear to have a chronic problem. As a result, there has been an increase in dentist consultations and in commercial business interests in products that eliminate the factors

\footnotetext{
* Correspondence: salvatore.settineri@unime.it

'Department of Neuroscience, Psychiatry and Anaesthesiology, University of Messina, Via Consolare Valeria, 1, 98100 Messina, Italy
}

responsible for halitosis [3]. In $80-90 \%$ of cases, halitosis is due not only to poor oral hygiene and other conditions linked to the oral cavity, but also to dental problems, such as periodontitis and gingivitis $[4,5]$. However, there are other possible extrinsic causes, e.g. smoking, alcohol, bad diet and sociodemographic factors $[6,7]$. Studies performed have revealed that halitosis is due to the presence of volatile sulfur compounds (VSCs) that originate from the mouth or from the air exhaled therefrom [8-10]. Interestingly, a study on the presence of VSCs did not observe any significant differences on the prevalence of halitosis linked to gender. From this study, it therefore seems that women are more worried than men about their own oral malodor, which highlights the role of the mouth in relationships [11]. 
Many studies on self-reported halitosis have stressed that the problem of halitosis is often not self-perceived $[6,7,12]$., Few studies in the literature have highlighted the links between halitosis and emotions, e.g. anxiety [13]. Nevertheless, the relations between anxiety and halitosis have been analyzed with clinical observations suggesting that anxious situations may increase VSC concentration thus causing halitosis [14].

One specific anxious situation is dental anxiety, defined as the response to stressful dental stimuli and to dentist-patient relations $[15,16]$. The impact of dental anxiety on appropriate dental care would appear to be considerable $[17,18]$.

The aim of this study is to examine the links between self-reported halitosis and factors related to emotional state, specifically dental anxiety.

\section{Methods \\ Patients}

The sample comprised 1052 subjects, 623 females and 388 males (41 subjects omitted gender) aged between 15 and 65 years old. Subjects were recruited, after giving their informed consent, in the waiting room of dental clinics of Messina and Reggio Calabria. The recruited subjects declared that they were at the dental clinic either for a first consultation or for a check-up for one of the following reasons: caries, dental cleaning, whitening, dental jewels, tartar, an abscess, dental extraction, filling, devitalization, bleeding or inflamed gums, brace, dental crown, dentures, dental surgery, pain, pyorrhea, self-reported halitosis or to accompany a patient.

Subjects agreed to fill in the protocol as a contribution to scientific research. The time spent by participants to fill in the protocol was between 90 and 120 minutes. The study project was approved by the Ethical Committee of Messina Prot. $\mathrm{N}^{\circ}$ E392/06 (additional file $\mathrm{n}^{\circ} 1$ ). Written and verbal informed consent to participate in the study was obtained from all subjects or their relative.

\section{Study Instruments}

The protocol given to subjects was made up of the following:

1. Self-report Questionnaire to detect self-reported halitosis and other variables possibly linked to it: sociodemographic data, presence or absence of medical and dental pathologies, any allergies, oral hygiene practices, medication, smoking and alcohol consumption, the importance attributed to one's own mouth and that of others. Medical and dental pathologies were evaluated both individually and by grouping them into the following categories: for medical pathologies - gastrointestinal tract disorders: liver diseases, gastritis, ulcers; urinary system disorders: renal disease, prostate; blood diseases: anemia, rheumatic fever, other blood disorders; infections: hepatitis, sexually transmitted diseases; cardiocirculatory diseases: heart disease, heart murmur, hypertension, hypotension; respiratory diseases: emphysema, tuberculosis, asthma; diabetes; thyroid disease; skin problems; carcinoma; glaucoma; mental disorders: epilepsy, psychiatric disorders, anxiety and for dental pathologies - gingival problems; sensitive and loose teeth; bruxism; pyorrhea (additional file ${ }^{\circ} 2$ ).

2. Dental Anxiety Scale (DAS) $[15,16,19]$ containing 19 items. This scale is divided into two parts. The first part (DAS 1) is made up of 6 items. The first five items explore the traits of dental anxiety of the patient. The replies are given using a score from 0 to 4 , with a total range for this first part of between 0 and 20. The total score was considered to indicate a low anxiety level if $\leq$ 14 and a high level where $\geq 15$.

Item 6 of DAS 1 looks at dental anxiety induced by specific dental stimuli using six sub-items: injection needles (6a), drill noise (6b), pain of treatment (6c), the smell of teeth being drilled (6d), a feeling of suffocation/ gagging/lack of air (6e), the reclined position of the dentist chair (6f). Each answer is scored from 1 (most frightening) to 7 (least frightening).

The second part (DAS 2), containing 13 items, explores dental anxiety relating to dentist-patient relations. Replies are assigned a score on a descending scale from 2 to 0 , with a cumulative score range of between 0 and 26. A judgment regarding the professionalism or respect for the dentist is implicit in all of the items. Anxiety level was considered to be either low (total score $\leq 12$ ) or high (total score $\geq 13$ ).

\section{Statistical analysis}

Data was analyzed using the Statistical Package for Social Sciences version 16.6 [20]. Means and frequency distributions were calculated for all study variables. The chi-square test was used to examine the links between self-perceived halitosis and variables studied by the selfreport questionnaire (age range, gender, level of education, occupational status, medical and dental pathologies - both singly and grouped, allergies, oral hygiene practices, medication, smoking and alcohol consumption). The mean differences between the two groups (with self-perceived halitosis and without) as regards dental anxiety (two separate subscales of DAS, specific dental fear and dentist-patient relations), and the importance attributed to one's own mouth and that of others were examined using the student's t-test. Multivariable analysis using binary logistic regression was performed to examine the importance of the various factors to the presence of self-reported halitosis in our sample. The regression model used the dependent variable of self-perceived halitosis dichotomized into "yes" 
or "no". The variables entered in the model, which are based on evidence in the literature about causes related to halitosis, were: relational dental anxiety (DAS 2 ), age $>30$ years, female gender, general anxiety, poor oral hygiene, alcohol consumption, urinary system pathologies and gingival diseases.

Adjusted odds ratios and corresponding 95\% confidence intervals $(95 \% \mathrm{CI})$ were generated for all variables.

\section{Results}

The sociodemographic characteristics of subjects are summarized in table 1.

The mean age of all participants was 35.12 years (s.d. $=19.38$; range 15-65 years). Females accounted for $59.2 \%$ of the sample. As regards level of education and occupation, $30.1 \%$ of the sample had graduated from high school and $36.7 \%$ of the subjects were unemployed.

The prevalence of self-reported halitosis in this sample was $19.39 \%(n=204$; table 1$)$. The sociodemographic characteristics of subjects reporting halitosis compared to the total sample are summarized in table 2 . The majority of subjects reporting self-perceived halitosis fell into the following categories: age $>30$ years $(p<0.001)$, female gender $(\mathrm{p}<0.001)$, high school graduate $(\mathrm{p}<0.050)$,

Table 1 Sociodemographic characteristics of the sample.

\begin{tabular}{|c|c|}
\hline Variables & N (\%) \\
\hline \multicolumn{2}{|l|}{ Age } \\
\hline Mean & 35.12 \\
\hline s.d. & 19.38 \\
\hline \multicolumn{2}{|l|}{ Sex } \\
\hline not stated & 41 (3.9\%) \\
\hline Male & $388(36.09 \%)$ \\
\hline Female & $623(59.2 \%)$ \\
\hline \multicolumn{2}{|l|}{ Education } \\
\hline not stated & $385(36.6 \%)$ \\
\hline Elementary school & $32(3.0 \%)$ \\
\hline Middle school & $142(13.5 \%)$ \\
\hline High school graduate & $317(30.1 \%)$ \\
\hline University degree & $176(16.7 \%)$ \\
\hline \multicolumn{2}{|l|}{ Occupation } \\
\hline Unemployed & $386(36.7 \%)$ \\
\hline Student & $193(18.3 \%)$ \\
\hline Housewife & $55(5.2 \%)$ \\
\hline Manual worker & 37 (3.5\%) \\
\hline Clerical worker & $143(13.6 \%)$ \\
\hline Teacher & $65(6.2 \%)$ \\
\hline Professional & $120(11.4 \%)$ \\
\hline Retired & $53(5.0 \%)$ \\
\hline \multicolumn{2}{|l|}{ Self-reported Halitosis } \\
\hline yes & $204(19.39 \%)$ \\
\hline no & $848(80.61 \%)$ \\
\hline
\end{tabular}

Total sample: $\mathrm{N}=1052$
Table 2 Sociodemographic characteristics of subjects with self-perceived halitosis.

\begin{tabular}{|c|c|c|c|c|}
\hline Variables & $\begin{array}{c}\mathrm{N}(\%) \\
\text { halitosis }\end{array}$ & N.total & $\chi^{2}$ & $p$-value \\
\hline \multicolumn{5}{|l|}{ Age } \\
\hline not stated & $8(3.9 \%)$ & $75(7.1 \%)$ & 129.879 & $\mathrm{p}<0.001$ \\
\hline$<30$ & $48(23.7 \%)$ & $413(39.4 \%)$ & & \\
\hline$>30$ & $108(72.4 \%)$ & $564(53.5 \%)$ & & \\
\hline \multicolumn{5}{|l|}{ Gender } \\
\hline not stated & $36(17.6 \%)$ & 41 (3.9\%) & 133.387 & $p<0.001$ \\
\hline Male & $79(38.7 \%)$ & $388(36.9 \%)$ & & \\
\hline Female & $89(43.6 \%)$ & $623(59.2 \%)$ & & \\
\hline \multicolumn{5}{|l|}{ Education } \\
\hline not stated & $82(40.2 \%)$ & $385(36.6 \%)$ & 9.504 & $\mathrm{p}<0.050$ \\
\hline Elementary school & $10(4.9 \%)$ & $32(3.0 \%)$ & & \\
\hline Middle school & $32(15.7 \%)$ & $142(13.5 \%)$ & & \\
\hline High school graduate & $46(22.5 \%)$ & $317(30.1 \%)$ & & \\
\hline University degree & $34(16.7 \%)$ & $176(16.7 \%)$ & & \\
\hline \multicolumn{5}{|l|}{ Occupation } \\
\hline Unemployed & 77 (37.7\%) & 386 (36.7\%) & 29.777 & $p<0.001$ \\
\hline Student & $16(7.8 \%)$ & 193 (18.3\%) & & \\
\hline Housewife & $12(5.9 \%)$ & $55(5.2 \%)$ & & \\
\hline Manual worker & $13(6.4 \%)$ & $37(3.5 \%)$ & & \\
\hline Clerical worker & $29(14.2 \%)$ & $143(13.6 \%)$ & & \\
\hline Teacher & $16(7.8 \%)$ & $65(6.2 \%)$ & & \\
\hline Professional & $23(11.3 \%)$ & $120(11.4 \%)$ & & \\
\hline Retired & $18(8.8 \%)$ & $53(5.0 \%)$ & & \\
\hline
\end{tabular}

unemployed $(\mathrm{p}<0.001)$. Table 3 reports the clinical characteristics which were statistically significant for subjects with self-reported halitosis compared to the total sample: physical diseases, dental pathologies, oral hygiene practices, problems concerning stress and anxiety.

Dental anxiety levels for the two groups of subjects (self-reported halitosis yes/no) highlighted statistically significant average differences between the two groups by reference to the two components of the scale: specific dental anxiety (DAS 1: mean $=11.00$, s.d. $=4.189, \mathrm{t}=$ $3.99, \mathrm{p}<0.001$ ) and relational dental anxiety (DAS 2 : mean $=22.05$, s.d. $=6.227, \mathrm{t}=4.498, \mathrm{p}<0.001)$.

The analysis also looked at statistically significant differences between the two groups (self-reported halitosis yes/no) as regards the importance attributed to the one's own mouth and that of others. Differences arose for the averages relating to the importance given to the mouth of others between subjects with self-reported halitosis $($ mean $=6.14$ and s.d. $=3.11, \mathrm{p}<0.001)$, and subjects without (mean $=7.39$ and s.d. $=2.76$, $\mathrm{p}<0.001$ ). Similarly, differences emerged for the importance attributed to one's own mouth between subjects with self-reported halitosis (mean $=6.61$ and s.d. $=3.31, \mathrm{p}<0.001)$ and subjects without (mean $=$ 8.18 and s.d. $=2.64, \mathrm{p}<0.001)$. 
Table 3 Clinical characteristics of subjects with self-perceived halitosis.

\begin{tabular}{ccccc}
\hline Variables & $\mathbf{N}$ halitosis & $\mathbf{N}$ total & $\boldsymbol{\chi}^{\mathbf{2}}$ & $\mathbf{p}$-value \\
\hline Anxiety & $74(36.3 \%)$ & $360(34.2 \%)$ & 63.846 & $\mathrm{p}<0.001$ \\
Anxiety data missing & $26(12.7 \%)$ & $38(3.6 \%)$ & & \\
Stress & $93(45.6 \%)$ & $455(43.3 \%)$ & 57.048 & $\mathrm{p}<0.001$ \\
Smoking & $61(29.9 \%)$ & $293(27.9 \%)$ & 18.371 & $\mathrm{p}<0.001$ \\
Alcohol & $43(21.1 \%)$ & $182(17.3 \%)$ & 103.696 & $\mathrm{p}<0.001$ \\
Dental problems & & & & \\
gum problems & $124(60.8 \%)$ & $367(34.9 \%)$ & 74.726 & $\mathrm{p}<0.001$ \\
sensitive teeth & $115(56.4 \%)$ & $495(47.1 \%)$ & 8.822 & $\mathrm{p}<0.005$ \\
Oral hygiene & & & & \\
Yes & $39(19.1 \%)$ & $310(29.5 \%)$ & 13.044 & $\mathrm{p}<0.001$ \\
No & $165(80.9 \%)$ & $742(70.5 \%)$ & & \\
Anemia & $44(21.6 \%)$ & $139(13.2 \%)$ & 43.032 & $\mathrm{p}<0.001$ \\
Thyroid & $33(16.2 \%)$ & $109(10.4 \%)$ & 96.387 & $\mathrm{p}<0.001$ \\
Allergies & $92(45.1 \%)$ & $443(42.1 \%)$ & 7.477 & $\mathrm{p}<0.005$ \\
Asthma & $25(12.3 \%)$ & $91(8.7 \%)$ & 83.401 & $\mathrm{p}<0.001$ \\
Taking medication & $82(40.2 \%)$ & $328(31.2)$ & 9.591 & $\mathrm{p}<0.005$ \\
Skin diseases & $44(21.6 \%)$ & $133(12.6 \%)$ & 44.66 & $\mathrm{p}<0.001$ \\
Gastro-intestinal & $62(30.4 \%)$ & $249(23.7 \%)$ & 89.263 & $\mathrm{p}<0.001$ \\
Urinary system & $67(32.8 \%)$ & $196(18.6 \%)$ & 33.718 & $\mathrm{p}<0.001$ \\
\hline
\end{tabular}

The logistic regression analysis results are presented in table 4 . The factors most strongly linked with self-perceived halitosis are: alcohol consumption (O.R. $=0.47, \mathrm{p}=$ $0.001)$, gingival pathologies (O.R. $=0.39, \mathrm{p}=0.001)$; age > 30 years (O.R. $=1.01, \mathrm{p}=0.003)$, urinary system pathologies (O.R. $=0.47, \mathrm{p}=0.003)$ and relational dental anxiety (DAS 2: O.R. $=1.04 ; \mathrm{p}=0.005)$. The other factors linked with self-perceived halitosis were: female gender (O.R. = $0.71, \mathrm{p}=0.041)$, suffering general anxiety $(\mathrm{O} . \mathrm{R} .=0.66, \mathrm{p}=$ $0.010)$ and poor oral hygiene (O.R. $=0.65, \mathrm{p}=0.040)$.

\section{Discussion}

Oral malodor seems to affect a large percentage of the general population and presents an etiology made up of several important linked factors (biological, dental, psychopathological). In our study the rate of self-reported halitosis was $19.39 \%$ and this revealed personal awareness

Table 4 Logistic regression analysis of factors associated with self-reported halitosis.

\begin{tabular}{ccccc}
\hline Variable & $\boldsymbol{\beta}$ (E.S.) & O.R. & C.I. & p-value \\
\hline Age $>30$ & $0.01(0.00)$ & 1.01 & $1.00-1.02$ & 0.003 \\
Female gender & $-0.33(0.16)$ & 0.71 & $0.51-0.98$ & 0.041 \\
DAS2 & $0.04(0.01)$ & 1.04 & $1.01-1.07$ & 0.005 \\
General anxiety & $-0.40(0.15)$ & 0.66 & $0.49-0.90$ & 0.010 \\
Oral hygiene & $-0.42(0.20)$ & 0.65 & $0.43-0.98$ & 0.040 \\
Gum disease & $-0.93(0.17)$ & 0.39 & $0.27-0.55$ & 0.001 \\
Alcohol consumption & $-0.73(0.16)$ & 0.47 & $0.34-0.66$ & 0.001 \\
Urinary system & $-0.75(0.21)$ & 0.46 & $0.30-0.70$ & 0.003 \\
\hline
\end{tabular}

Significance of the model: $\chi^{2}=1034.86 ; p<0.001$. of one's own bad breath. Nevertheless, like other studies it is possible that not all the subjects with halitosis expressly declared to be suffering from it $[6,7,12]$. This means perception of halitosis may differ in line with the subjectivity of perception [21]. This aspect was important in our study which evaluated the relation between the anxiety dimension and self-perceived halitosis. Moreover, the percentage of female participants (59.2\%) in the sample with self-perceived halitosis poses questions on the links existing between female gender and anxiety.

Putting aside the limitations of a self-report to evaluate halitosis, we used such a scale to measure dental anxiety in our study [22]. The reliability of this scale has been demonstrated in previous studies $[15,16]$.

The findings highlight, in line with other studies, that the etiopathogenesis of halitosis is linked to medical problems such as urinary system disorders, anemia, gastrointestinal tract disorders, skin problems, allergies, and thyroid problems $(\mathrm{p}<0.001$; table 3$)$. Nevertheless, our study also highlighted other causes to be linked, including alcohol consumption, smoking and poor oral hygiene $(\mathrm{p}<0.001$; table 3$)$. These data were further validated by regression analysis (table 4 ).

The most interesting results of this study are concerned with anxiety. Our study provides possible explanations, both biological and psychological, for the relations found between anxious situations and increased VSCs [14]. Biological, because subjects reporting halitosis are preponderantly female and they present significant associations with thyroid problems correlated in the literature with anxiety problems [23-25]; psychological, due to the declared presence of general anxiety problems $(36.3 \%$; $\mathrm{p}<0.001$; table 3 ) and stress (45.6\%; p < 0.001; table 3).

Moreover, the specific study on the presence of dental anxiety within the group of subjects with self-reported halitosis revealed significant average differences for both subscales of dental anxiety, phobic (DAS 1: mean = 11.00 , s.d. $=4.189, \mathrm{t}=3.99, \mathrm{p}<0.001)$ and dentistpatient relations (DAS 2: mean $=22.05$, s.d. $=6.227, \mathrm{t}=$ $4.498, \mathrm{p}<0.001)$. From the analysis it seems that subjects reporting halitosis were, on average, more phobic and less willing to interact with the dentist in comparison to subjects not reporting halitosis. Moreover, the regression analysis provided additional evidence as regards relational dental anxiety (DAS 2; table 4).

In addition, there were differences concerning the importance attributed to one's own mouth and that of others. Subject with self-reported halitosis on average placed less importance both on their own mouth (mean $=6.14$ and s.d. $=3.11, \mathrm{p}<0.001)$ and that of others $($ mean $=6.61$ and s.d. $=3.31, \mathrm{p}<0.001)$. This finding within the group reporting halitosis corresponds with the presence of poor oral hygiene, gingival problems and relational anxiety (referred to the dentist). 
The question of which measure to use in an oral health context has been the subject of intense research efforts in recent years [26-28]. A recent study showed that good oral health has a beneficial effect on the quality of life due to its impact on appearance, breath, comfort, sleep, mood and social life [29]. Some studies have shown that dental anxiety depends on self-awareness of treatment [30,31]. In general, self-awareness is defined as the perception of oneself, and, more specifically, as the tendency to think about and evaluate aspects of oneself that are subjugated to stressful events (e.g. dental stimuli) $[32,33]$. This is why oral procedures are perceived as being so stressful that they can cause acute symptoms of anxiety, such as excessive apprehension, irritability, tension due to anticipated harm, and can lead to avoidance of dental treatment $[34,35]$.

Dental fear is a common phenomenon the world over; approximately $25 \%$ of patients avoid visits and treatments, and approximately $10 \%$ reach phobic levels of anxiety [19]. This problem is of great importance for several reasons: a) avoidance causes poorer oral health and quality of life; b) high levels of anxiety and phobias may affect the dentist-patient relationship. The link between a lack of adequate dental health education and high levels of dental anxiety is important, because it causes fear in patients and poor compliance [28]. Dental anxiety relating to dentist-patient relations could be circumvented through good dental health education, regular dental visits, good patient-dentist relations and suitable communication with patients. The correlated factors of an anxiogenic perception of the dentist and self-perceived halitosis also find common ground as regards their mental representation.

It would therefore be interesting to conduct studies that draw out the consideration of others in relation to self-perception with studies including variables such as gender and ethnic group.

\section{Conclusions}

Our study found anxiety to be one of the causes of selfreported halitosis. Halitosis therefore requires not only the professional care supplied by dentists, but also psychological support as it restricts relations with others. From this study emerges the need to promote not only healthy oral hygiene habits, but also to pay greater attention to the psychological aspects of the experience of seeing the dentist and undergoing dental treatment.

Additional file 1: Ethical Committee of Messina Prot. $\mathbf{N}^{\circ}$ E392/06 ethical notification.

Additional file 2: Self-report Questionnaire to detect self-reported halitosis and other variables possibly linked to it.

\section{Acknowledgements}

The authors would like to thank the patients, local investigators and clinical staff who participated in the study. The authors gratefully thank Ms. Susan H. Parker for the linguistic review.

\section{Author details}

'Department of Neuroscience, Psychiatry and Anaesthesiology, University of Messina, Via Consolare Valeria, 1, 98100 Messina, Italy. ${ }^{2}$ Department of Odontostomatology, University of Messina, Italy. ${ }^{3}$ SEFISTAT, Department of Economic, Financial, Social, Environmental, Statistical and Territorial Sciences, University of Messina, Italy.

\section{Authors' contributions}

SS: AT designed and coordinated the study; GT: SCG managed the statistical analysis; CM, AS: DM assisted in the conceptualization and planning of the data analysis and with manuscript preparation and review. All authors reviewed the manuscript critically for content and approved it for submission.

\section{Competing interests}

The authors declare that they have no competing interests.

Received: 30 July 2009 Accepted: 26 March 2010

Published: 26 March 2010

\section{References}

1. Bosy A: Oral malodor: philosophical and practical aspects. Journal of the Canadian Association 1997, 63:196-201.

2. Miyazaki H, Sakao S, Katoh Y, Takehara T: Correlation between volatile sulphur compounds and certain oral health measurements in the general population. Journal of Periodontology 1995, 66:679-84.

3. ADA Council on Scientific Affairs: Oral malodor. Journal of the American Dental Association 2003, 134:209-14.

4. Velde Van den S, Quirynen M, Van Hee P, Van Steenberghe D: Halitosis associated volatiles in breath of healthy subjects. Journal of Chromatography B 2007, 853:54-61.

5. Oho T, Yoshida Y, Shimazaki Y, Yamashita Y, Koga T: Characteristic of patients complaining of halitosis and the usefulness of gas chromatography for diagnosing halitosis. Oral Surgeny, Oral Medicine, Oral Pathology, Oral Radiology \& Endodontics 2001, 91(5):531-4.

6. Al-Ansari JM, Bordai H, Al-Sumait N, Al-Khabbaz AK, Al-Shammari KF, Salako N: Factors associated with self-reported halitosis in Kuwait patients. Journal of Dentistry 2006, 34:444-449.

7. Nalcaci R, Baran : Factors associated with self-reported halitosis (SRH) and perceived taste disturbance (PTD) in elderly. Archives of Gerontology and Geriatrics 2008, 46(3):307-16.

8. Hughes FJ, McNab R: Oral Malodour -a review. Archives of Oral Biology 2008, 53(Suppl):1-7.

9. Thrane PS, Young A, Jonski G, Rölla G: A new mouthrinse combining zinc and chlorhexidine in low concentrations provides superior efficacy against halitosis compared to existing formulations: a double-blind clinical study. Journal of Clinical Dentistry 2007, 18(3):82-6.

10. Rodriguez-Fernández J, López-Fernández R, Pereiro R, Menéndez M, Tejerina JM, Sicilia A, Sanz-Medel A: A sorbent tube for malodour monitoring. Talanta 2004, 62(2):421-426.

11. Smith CJ, Noll JA, Bryant JB: The Effect of Social Context on Gender selfConcept. Sex Roles 1999, 40:499-512.

12. Eli I, Baht R, Koriat H, Rosenberg M: Self-perception of breath odor. Journal of the American Dental Association 2001, 132(5):621-6.

13. Suzuki $N$, Yoneda $M$, Naito $T$, Iwamoto $T$, Hirofuji T: Relationship between halitosis and psychologic status. Oral Surgery, Oral Medicine, Oral Pathology and Endodontology 2008, 106(4):542-547.

14. Calil CM, Marcondes FK: Influence of anxiety on the production of oral volatile sulfur compounds. Life Sciences 2006, 79:660-664.

15. Corah NL: Development of a dental anxiety scale. Journal of Dental Research 1969, 48(4):596.

16. Corah NL, Gale EN, Illig SJ: Assessment of a dental anxiety scale. Journal of the American Dental Association 1978, 97(5):816-9. 
17. Vermaire $J H$, De Jongh A, Aartman JHA: Dental anxiety and quality of life: the effect of dental treatment. Community Dentistry and Oral Epidemiology 2008, 36:409-416.

18. Schuller AA, Willumsen T, Holst D: Are there differences in oral health and oral health behavior between individuals with high and low dental fear?. Community Dentistry and Oral Epidemiology 2003, 31:116-21.

19. Facco E, Zanette G, Manani G: Italian Version of Corah's Dental Anxiety Scale: Normative Data in Patients Undergoing Oral Surgery and Relationship With the ASA Psysical Status Classification. Anesthesia Progress 2008, 55(4):109-115.

20. SPSS: 16.0 version Chicago IL. USA 2007.

21. Anttila $S$, Knuuttila M, Ylöstalo P, Joukamaa M: Symptoms of depression and anxiety in relation to dental health behavior and self-perceived dental treatment need. European Journal of Oral Sciences 2006, 114(2):109-14.

22. Kvale $G$, Berggren $U$, Milgrom P: Dental fear in adults: a meta-analysis of behavioural interventions. Community Dentistry and Oral Epidemiology 2004, 32:250-64.

23. Kikuchi M, Komuro R, Oka H, Kidani T, Hanaoka A, Koshino Y: Relationship between anxiety and thyroid function in patients with panic disorder. Progress in Neuro-Psychopharmacology \& Biological Psychiatry 2005, 29:77-81.

24. Carta MG, Hardoy MC, Boi MF, Margotti S, Carpiniello B, Usai P: Association between panic disorder, major depressive disorder and celiac disease. A possible role of thyroid autoimmunity. Journal of Psychosomatic Research 2002, 53:789-93.

25. Cihan A, Demir O, Demir T, Aslan G, Comlekci A, Esen A: The relationship between premature ejaculation and hyperthyroidism. Journal of Urology 2009, 181:1273-1280.

26. Allen PF: Assessment of oral health related quality of life. Health and Quality of Life Outcomes 2003, 1:40.

27. Oktay EA, Koçak MM, Sahinkesen G, Topçu FT: The role of age, gender, education and experiences on dental anxiety. Gülhane Tip Dergisi 2009, 51:145-148.

28. Al-Omari WM, Al-Omiri MK: Dental anxiety among university students and its correlation with their field of study. Journal of Applied Oral Science 2009, 17(3):199-203.

29. Kumar S, Bhargav P, Patel A, Bhati M, Balasubramanyam G, Duraiswamy $P$, Kulkarni S: Does dental anxiety influence oral health-related quality of life? Observations from a cross-sectional study among adults in Udaipur district, India. Journal of Oral Sciences 2009, 51(2):245-254.

30. Samorodnitzky GR, Levin L: Self-assessed dental status, oral behavior, DMF, and dental anxiety. Journal of Dental Education 2005, 69(12):1385-9.

31. Kloostra PW, Eber RM, Inglehart MR: Anxiety, stress, depression, and patient's responses to periodontal treatment: periodontists' knowledge and professional behavior. Journal of Periodontology 2007, 78(1):64-71.

32. Economou GC, Honours B: Dental anxiety and personality: investigating the relationship between dental anxiety and self-consciousness. Journal of Dental Education 2003, 67(9):970-980.

33. Locker D: Psychological consequences of dental fear and anxiety. Community Dentistry and Oral Epidemiology 2003, 31(2):144-51.

34. Eli I, Koriat $H$, Baht R, Rosenberg M: Self-perception of breath odor: role of body image and psychopathologic traits. Perceptual and motor skills 2000, 91:1193-201.

35. Settineri S, Tat $\mu$ F, Fanara G: Gender differences in dental anxiety: is the chair position important?. Journal of Contemporary Dental Practice 2005, $15,6(1): 115-22$.

doi:10.1186/1477-7525-8-34

Cite this article as: Settineri et al: Self-reported halitosis and emotional state: impact on oral conditions and treatments. Health and Quality of Life Outcomes 2010 8:34.

\section{Submit your next manuscript to BioMed Central and take full advantage of:}

- Convenient online submission

- Thorough peer review

- No space constraints or color figure charges

- Immediate publication on acceptance

- Inclusion in PubMed, CAS, Scopus and Google Scholar

- Research which is freely available for redistribution

Submit your manuscript at www.biomedcentral.com/submit
Biomed Central 